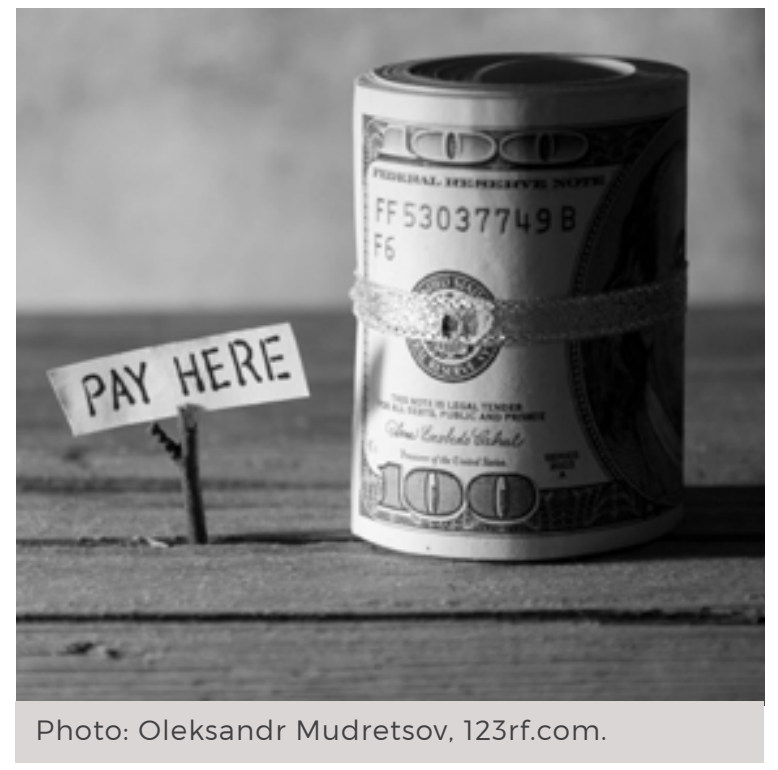

\section{Beyond the Great Paywall}

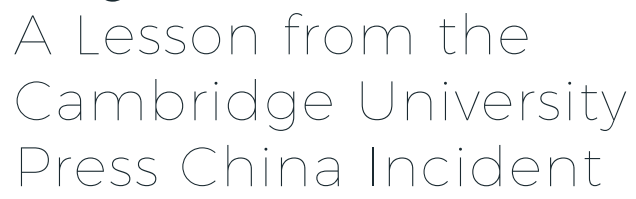

\section{Nicholas Loubere Ivan Franceschini}

On 18 August it was revealed that Cambridge University Press had complied with the demands of Chinese government censors to block access on its website in China to hundreds of 'politically sensitive' articles published in its prestigious The China Quarterly journal. The ensuing debate has generally overlooked the problematic nature of the commercial academic publishing industry. Isn't it time to take the profit motive out of the equation and to rediscover a certain measure of idealism in academia?
On 18 August it was revealed that Cambridge University Press (CUP) had complied with the demands of Chinese government censors to block access on its website in China to over three hundred 'politically sensitive' articles published in its prestigious The China Quarterly journal. This move was met with outrage in the academic community and beyond, with scholars criticising the Chinese government for the unprecedented extension of its heavy-handed censorship into foreignlanguage academia, and CUP for acquiescing to the demands. Prompted by this harsh response, on 21 August CUP reversed its stance, restoring access to the censored contents for its Chinese audience and making them available free of charge for all. While the reversal is certainly welcome and highlights the power that coordinated action on the part of the academic community can have, we feel that the ensuing debate has overlooked an issue of fundamental importance: the problematic nature of the commercial academic publishing industry. While CUP is listed as a charitable organisation, it is also a highly profitable operation. It brings in hundreds of millions of pounds in yearly revenues, and has extensive commercial interests in the Chinese market. As such, it should be unsurprising that they would be tempted to submit to such a request in order to preserve their access to Chinese consumers, even if we find it distasteful that they framed their choice as a pragmatic effort to continue long-term engagement with China. In light of this, we believe that this incident should not only be viewed as the exceptional capitulation of one specific publisher to China, but also as representative of a wider capitulation of academic publishing to commercial interests.

\section{The Contradiction of Contemporary Academic Publishing}

While there is certainly plenty of well justified outrage to go around, this incident 
exposes a paradox at the heart of contemporary academic publishing and its supposed role in the promotion of academic freedom-the fact that academics are required to hand over their research, which is usually supported by public funding, to publishers whose primary goal is to earn profit rather than make the material freely accessible to as wide an audience as possible. In addition to the The China Quarterly, most of the main journals in China Studies are currently published by major profit-oriented publishers-such as the China Journal (University of Chicago Press), the Journal of Contemporary China (Taylor \& Francis), and Modern China (SAGE). These publishers charge exorbitant prices for access to the articles. For instance, Taylor \& Frances charges forty-two USD for twentyfour-hour access to an article in the Journal of Contemporary China, effectively blocking anyone who does not have access through an institution that pays for the costly subscription. It might even be argued that this oppressive paywall system represents a different-and probably even much wider and more noxious-form of censorship than any imposed by the Chinese government. Indeed, while CUP's capitulation would have blocked access for a relatively small number of Chinese academics, the vast majority of Chinese citizens (as well as citizens elsewhere) are already blocked by the 'great paywall' of profit-oriented publishing.

It is important to remember that that academic publishing was not always like this. Many academic journals used to be published by scholarly associations or universities that were not seeking to maximise profits, but were rather aiming to simply cover their operational costs in order to further research in their fields. Journals also used to be motivated by broader academic ideals that went beyond the simple aspiration to achieve a higher 'impact factor'. This idealism justified the request that scholars provide the unpaid labour needed to keep these publications in operation by serving on editorial boards and doing peer-reviews-i.e. the work that actually makes the publications academic.

\section{Open Access as a Viable Alternative}

While the current situation is undoubtedly dire, there are obvious and workable alternatives to this system. A number of university presses, such as Amsterdam University Press and UCL Press, now offer open access options for their authors, and ANU Press is fully open access. Since scholars already do the editing and peer reviewing for all academic publications free of charge, the same people who populate the editorial boards of top journals and send out peer review requests could, conceivably, do the same work for open access publications. In fact, there are already a few successful examples of high quality open access journals in China Studies. For instance, the Journal of Current Chinese Affairs (JCCA) is published open access by the German Institute of Global and Area Studies. The JCCA has a highly respected editorial board, and its submissions undergo the same rigorous peer review process as any profit-oriented publication. The operation of the JCCA is facilitated by an open source publishing software called Open Journal Systems, which automates the submission process and much of the other work done by large publishers. The success of the JCCA points to the fact that, with a small budget to hire editorial assistants and a dedicated group of academics, it is possible to produce top-quality and rigorously peer-reviewed publications that are open to everyone and not profit-oriented. Unsurprisingly, however, the JCCA is not given its due recognition by the academic publishing establishment. It is not listed in Thomson Reuters' Social Science Citation Index nor is it given an 'official' impact factor by the corporation. This makes the journal a risky choice for early career academics needing to publish articles 
that 'count' for tenure. It is also unclear how monographs published by open access university presses are viewed by tenure committees.

In short, there are options available for academics to publish rigorously peerreviewed journal articles and books that are open to a much wider audience. Our first attempt at a 'proper' open access academic publication-the Made in China Yearbook 2016: Disturbances in Heaven, published by ANU Press this February-was downloaded more than four thousand times in only the first two months after publication, far more than the standard print run of three to five hundred copies produced by traditional publishers. In our opinion, besides leading to rightful condemnations of the censorship of the Chinese authorities and the vacillating behaviour of CUP, the recent incident should give academics pause when considering how to publish academic research, as well as the kind of academic work they engage in with the publishing industry. It will take senior academics to lead the way by establishing open access journals with quality editorial boards that ensure the highest standards-i.e. the work that is already done free of charge for large profit-oriented publishers. Senior academics should also explicitly signal to early career scholars and their institutions that high-quality open access publications are worth just as much as their profit-oriented counterparts for tenure and promotion.

\section{Rediscovering Idealism}

Ultimately, while the academic community should rightly be outraged over CUP's initial capitulation to China's demands, and worried about the increasing ability of Beijing to silence discourse it does not agree with both within and outside China, we believe that this incident exposes a much more serious threat to academic freedom represented by the wholesale adoption of commercial modes of academic publishing. CUP may have reversed its decision to capitulate to the Chinese censors, but there is a significant risk that other publishers, prompted by the same commercial incentives, will opt to self-censor. Indeed, under the condition of anonymity multiple publishers at the Beijing International Book Fair in August admitted to censoring content, and LexisNexis has also been revealed to have removed products in China at the request of the censors. As the country's economic might continues to grow, the party-state will find itself with more and more ability to directly influence the content of multinational profit-oriented publishers seeking access to the huge Chinese market. In this environment, the only way that we can preserve academic freedom from overreach from governments or other powerful economic actors is to take the profit motive out of the equation by rediscovering a certain measure of idealism and ensuring free access to our scholarship.

\section{Nicholas Loubere}

Nicholas Loubere is an Associate Senior Lecturer in the Study of Modern China at the Centre for East and South-East Asian Studies, Lund University. His research examines socio-economic development in rural China, with a particular focus on microcredit and the rural financial system.

\section{Ivan Franceschini}

Ivan Franceschini is a Marie Curie Fellow at $\mathrm{Ca}$ Foscari University of Venice and at the Australian Centre on China in the World. He is working on a project on Chinese labour in a global perspective. 